\title{
MicroRNA-494 promotes cancer progression and targets adenomatous polyposis coli in colorectal cancer
}

\author{
Ying Zhang ${ }^{1 \dagger}$, Lu Guo ${ }^{1,2 \dagger}$, Yuhuan Li ${ }^{1,2+}$, Gui-Hai Feng ${ }^{1}$, Fei Teng ${ }^{1,2}$, Wei Li ${ }^{1,2}$ and Qi Zhou ${ }^{1,2^{*}}$
}

\begin{abstract}
Background: Aberrant activation of the Wnt/ $\beta$-catenin signaling pathway is frequently observed in colorectal cancer (CRC). $\beta$-catenin is the major Wnt signaling pathway effector and inactivation of adenomatous polyposis coli (APC) results in nuclear accumulation of $\beta$-catenin. It has been suggested that inactivation of APC plays an important role in activation of the $\mathrm{Wnt} / \beta$-catenin pathway and in the progression of colorectal tumorigenesis. However, the mechanism through which APC mediates colorectal tumorigenesis is not understood. Increasing evidence suggests that the dysregulation of microRNAs (miRNAs) is involved in colorectal tumorigenesis. Although miR-494 has been reported as being an upregulated miRNA, the interplay between miR-494 and APC-mediated colorectal tumorigenesis progression remains unclear.
\end{abstract}

Methods: The expression of miR-494 in tissues from patients diagnosed with CRC was analyzed using a microarray and real-time PCR. The effects of miR-494 on cell proliferation and tumorigenesis in CRC cells were analyzed by flow cytometry, colony formation assays, BrdU incorporation assays, and CCK8 assays. The correlation between miR-494 expression and APC expression, as well as the mechanisms by which miR-494 regulates APC in CRC were also addressed.

Results: miR-494 was significantly upregulated in CRC tissues, and this increase was negatively associated with APC expression. APC was confirmed to be a direct target of miR-494 in CRC. Furthermore, overexpression of miR494 induced Wnt/ $\beta$-catenin signaling by targeting APC, thus promoting CRC cell growth.

Conclusions: This study provides novel insights into the role of miR-494 in controlling CRC cell proliferation and tumorigenesis, and identifies miR-494 as a potential prognostic marker and therapeutic target.

Keywords: Colorectal cancer, microRNA, miR-494, Apc

\section{Background}

Colorectal cancer (CRC) is one of the most common malignancies in the world, with over one million new patients diagnosed every year [1]. CRC progression is accompanied by the accumulation of mutations in tumor-suppressor genes and oncogenes, including adenomatous polyposis coli (APC) [2]. Inactivation of $A P C$ is a major initiating event in colorectal tumorigenesis [3]. Specifically, mutations in $A P C$ are a leading cause of CRC [4]. Mutations in APC have been found in

\footnotetext{
* Correspondence: zhouqi@ioz.ac.cn

${ }^{\dagger}$ Equal contributors

${ }^{1}$ State Key Laboratory of Stem Cell and Reproductive Biology, Institute of

Zoology, Chinese Academy of Sciences, Beijing 100101, China

¿University of Chinese Academy of Sciences, Beijing 100049, China
}

all patients diagnosed with familial adenomatous polyposis, as well as in almost $90 \%$ of patients diagnosed with CRC [5]. Most of the mutations in APC generate premature stop codons leading to truncated proteins that lack $\beta$-catenin binding sites. APC-free $\beta$-catenin stimulates the Wnt signaling pathway, leading to the active transcription of target genes such as c-Myc and cyclin D1, thereby promoting tumorigenesis [6, 7].

$\mathrm{APC}$ and Axin serve as essential scaffolds for glycogen synthase kinase 3 beta (GSK-3 $\beta$ ) and $\beta$-catenin, and impaired association of APC, Axin, with $\beta$-catenin leads to constitutive activation of the Wnt signaling pathway $[8,9]$. In the intestine, the canonical Wnt pathway maintains the proliferative cell layer in the crypts [10]. Upon 
activation of the Wnt pathway, $\beta$-catenin is released from the cytoplasmic complex formed by APC, Axin, and GSK-3 $\beta$. Consequently, $\beta$-catenin is then able to bind the T-cell factor/lymphoid enhancer factor binding factor $(\mathrm{TCF} / \mathrm{LEF})$ transcription factors, resulting in increased transcription of downstream targets such as c-Myc or cyclin D1. In contrast, in differentiated intestinal epithelial cells, APC acts as a negative regulator of the Wnt signaling pathway by binding to $\beta$-catenin in order to induce its degradation [11].

MicroRNAs (miRNAs), are a class of naturally occurring small, noncoding RNAs comprising of 19 to 25 nucleotides, that are an important class of cellular regulators that modulate gene expression, and thereby influence cell fate and function [12-16]. miRNAs function by binding to target mRNAs via sequence complementarity, and repress translation or induce degradation of their target mRNAs $[17,18]$. So far, a number of miRNAs have been ascribed oncogenic or tumor-suppressive functions, and they are involved in almost every type of cancer, including breast, lung, gastric carcinoma, and CRC [19-22]. Some miRNAs have been studied for their roles in colorectal carcinogenesis [23-26]. For example, miR-494 has previously been reported to be upregulated in $\mathrm{CRC}$, and it promotes cell migration and invasion in CRC by directly targeting phosphatase and tensin homolog (PTEN) [27]. The roles and potential mechanisms of miRNAs, mediated by APC, in CRC are still largely unknown.

Here, we report that miR-494 activates the Wnt/ $\beta$-catenin signaling pathway by suppressing the expression of $\mathrm{APC}$ and consequently plays an important role in the development and progression of CRC.

\section{Methods}

Tissue specimens and immunohistochemistry (IHC) staining The Ethics Committee of Institute of Zoology approved this study, and all patients gave their informed consent prior to surgery. Colon carcinoma tissues from human patients were obtained from Beijing 301 Military General Hospital (Beijing, China). The patients clinical characteristics are shown in Table 1. Detailed information including demography, clinical characteristics, histopathology, APC mutation status, and survival status were collected for all patients. Patients were followed after surgical treatment with a median follow-up of 61 months (range, 8-122 months). All patients were staged based on the Tumor-Node-Metastasis (TNM) classification. For mRNA extraction, samples were frozen in liquid nitrogen immediately after surgical removal and maintained at $-80{ }^{\circ} \mathrm{C}$ until use. Additional samples were fixed in $10 \%$ neutral-buffered formalin overnight, processed, paraffin embedded, and sectioned. A patient tissue with one synonymous mutation in the codon encoding amino acid 1828 in APC, that did not cause a change in amino acid
Table 1 Clinical correlation between miR-494 expression and other clinicopathological characteristics in CRC

\begin{tabular}{|c|c|c|c|}
\hline Characteristics & $\mathrm{N}$ of cases & High miR-494 group & $P$-value \\
\hline Age (years) & 46 & 20 & 0.476 \\
\hline$\leq 60$ & 24 & 11 & \\
\hline$>60$ & 22 & 9 & \\
\hline Sex & & & 0.887 \\
\hline Men & 28 & 12 & \\
\hline Women & 18 & 8 & \\
\hline TNM stage & & & ${ }^{*} 0.004$ \\
\hline $\mid+\|$ & 19 & 6 & \\
\hline$I I I+I V$ & 27 & 14 & \\
\hline Differentiation & & & ${ }^{*} 0.034$ \\
\hline Well & 35 & 14 & \\
\hline Poorly & 11 & 6 & \\
\hline APC mutation status & & & 0.567 \\
\hline Wild-type & 5 & 2 & \\
\hline Mutant & 41 & 18 & \\
\hline Survival status & & & 0.476 \\
\hline Dead & 22 & 9 & \\
\hline Alive & 24 & 11 & \\
\hline
\end{tabular}

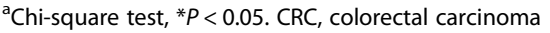

sequence, was selected for IHC analysis. IHC analysis was performed using $3 \mu \mathrm{m}$ sections which were incubated with an anti-APC antibody (Abcam catalog no. 154906) overnight at $41{ }^{\circ} \mathrm{C}$ in a humidified chamber, followed by incubation with an HRP-conjugated secondary antibody for $2 \mathrm{~h}$. Staining was completed after 5 to 10 min incubation with 3,3'-diaminobenzidine (DAB) as substrate, which resulted in a brown-colored precipitate at the antigen site.

\section{Cell lines and cell culture}

Human colon cancer cell lines were obtained from American Type Culture Collection (Manassas, VA). HCT-116 and HT-29 cells were maintained in Dulbecco's modified Eagle's medium (DMEM) supplemented with $10 \%$ fetal bovine serum (FBS). Cells were maintained in a humidified incubator equilibrated with $5 \% \mathrm{CO}_{2}$ at $37^{\circ} \mathrm{C}$.

\section{Microarray analysis}

Total RNA was extracted from 17 tumor tissues and paired normal colorectal tissues using TRIzol reagent (Invitrogen). miRNA microarray profiling was performed as previously described [28]. Data analysis was performed using GeneSpring GX software (Agilent). An miRNA was designated as overexpressed if the expression in tumor tissues was greater than 2.0-fold that in normal colorectal epithelial tissues. 


\section{a}

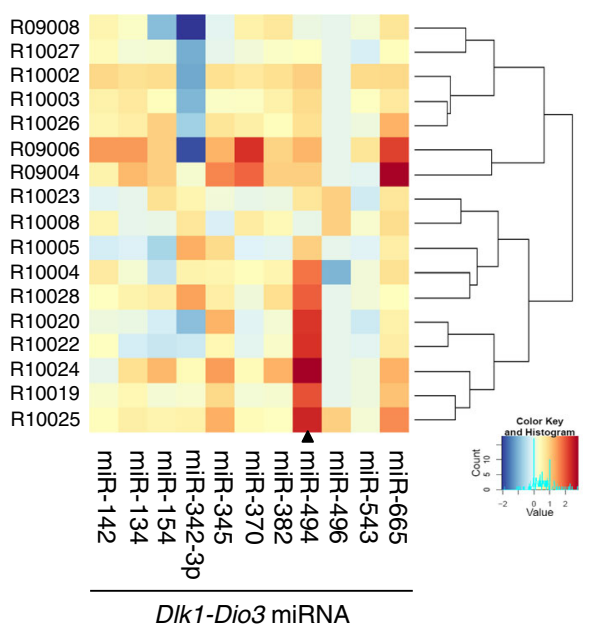

b

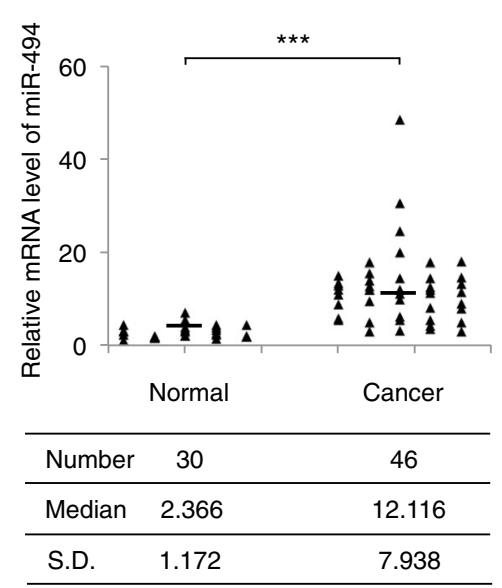

C

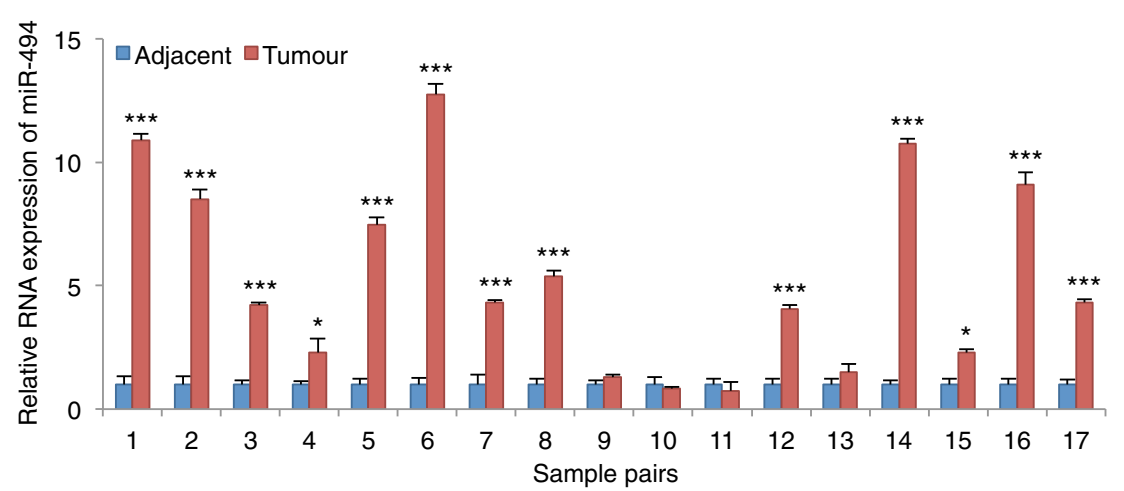

Fig. 1 miR-494 is overexpressed in CRC. a Hierarchical clustering of miRNA expression profiles from the Dlk1-Dio3 region obtained from 17 pairs of CRC tissues compared with adjacent, non-tumor tissues. b The miR-494 expression levels in CRC tissues and non-tumor tissues, evaluated by real-time PCR. $\mathbf{c}$ The expression levels of miRNA-494 in paired samples of CRC tissues and matched adjacent non-tumor tissues. ( ${ }^{*}, P<0.05$; ${ }^{* * *}, P<0.001$, Student's $t$-test)

\section{Real-time PCR detection of mature miRNAs}

Total RNA was isolated using TRIzol reagent (Invitrogen) according to the manufacturer's protocol. All-in-One ${ }^{\text {Tx }}$ miRNA First-Strand cDNA Synthesis Kit (Genecopoeia) was used to transcribe $10 \mu \mathrm{L}$ of purified RNA. Real-time PCR, using miR-specific primers and universal adaptor PCR primers (Genecopoeia), was performed with a Stratagene Mx3000P QPCR System (Genetimes Technology, Shanghai, China). The reactions were incubated in a 96 well plate at $95{ }^{\circ} \mathrm{C}$ for $10 \mathrm{~min}$, followed by 40 cycles at $95{ }^{\circ} \mathrm{C}$ for $15 \mathrm{~s}$, and $60{ }^{\circ} \mathrm{C}$ for $1 \mathrm{~min}$. All reactions were run in triplicate.

\section{RNA extraction and real-time PCR}

Total RNA was isolated as described above. For reverse transcription into cDNA, $1 \mu \mathrm{g}$ of RNA from each sample was incubated with random primers and then subjected to real-time PCR. Real-time quantification was performed using a Stratagene Mx3000P quantitative PCR system (Genetimes Technology, Shanghai, China). The reaction solutions were incubated in a 96 -well plate at $95{ }^{\circ} \mathrm{C}$ for $10 \mathrm{~min}$, followed by 40 cycles at $95{ }^{\circ} \mathrm{C}$ for $15 \mathrm{~s}$, and $60{ }^{\circ} \mathrm{C}$ for $1 \mathrm{~min}$. All reactions were run in triplicate. The primer pairs used were as follows: APC, 5'-CTGCGGACCG AGGTTGGCTC-3' (forward) and 5' -CTTCCTGCCAGA CGCTCGCC-3' (reverse); and GAPDH, 5' -CTCTGCTC CTCCTGTTCGAC-3' (forward) and 5'-CGACCAAATC CGTTGACTCC-3' (reverse).

\section{Oligonucleotide transfections}

All commercial miRNAs and the APC targeted small interfering RNAs (siRNAs) were synthesized and purified by RiboBio Co. (Guangzhou, China). The APC siRNA sequences used were APC-siRNA1, 5' -GGATCA GCCTATTGATTAT-3' and APC-siRNA2, 5'-GTACGC CAGTCAACTTTCA-3'. Transfections of the aforementioned miRNAs and siRNAs were performed using Lipofectamine 2000 (Invitrogen), according to the manufacturer's instructions. 
a

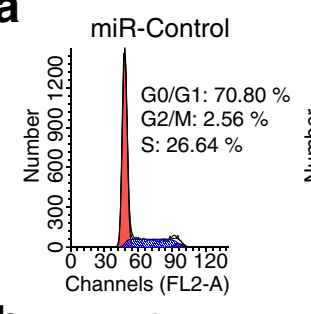

b

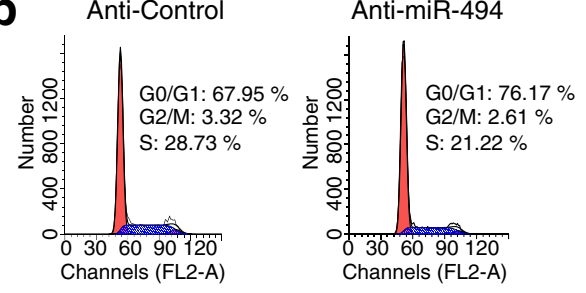

C

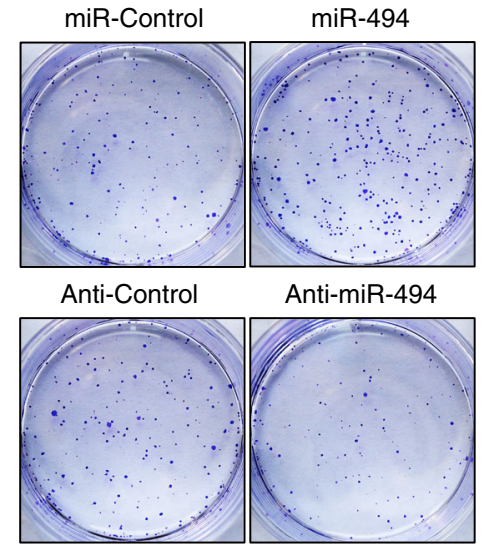

d

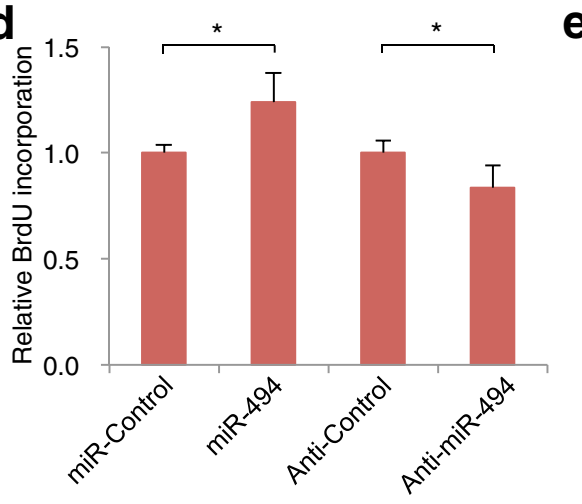

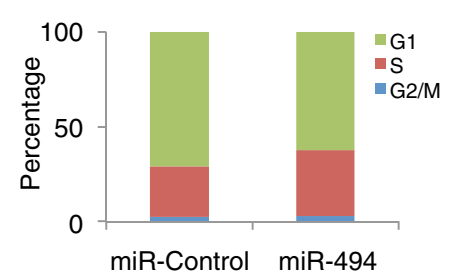

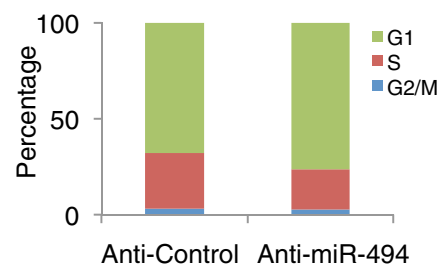

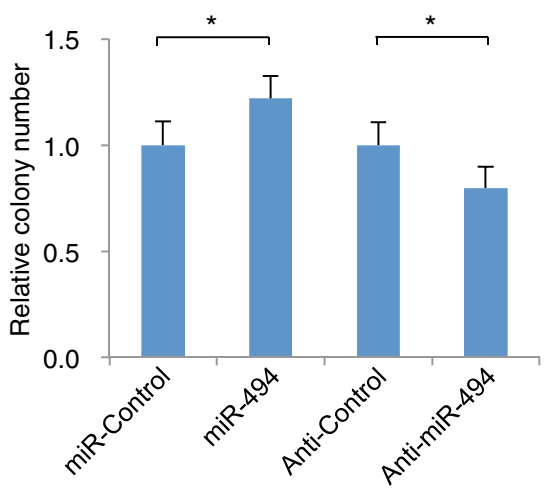

e

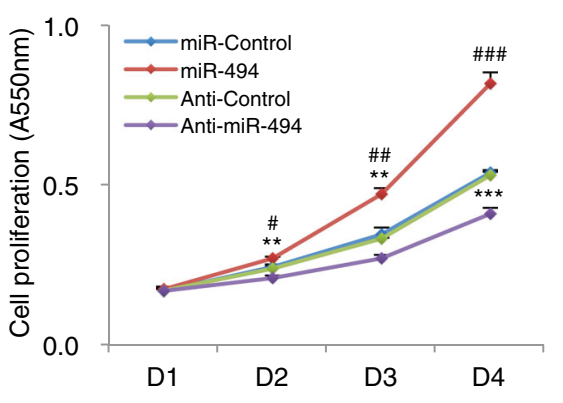




\begin{abstract}
(See figure on previous page.)
Fig. 2 miR-494 promotes the proliferation of CRC cells. a The effect of miR-494 overexpression on cell cycle progression. HCT-116 cells were transfected with a control miRNA or a miR-494 mimic for $24 \mathrm{~h}$ and then switched to conditioned medium without serum for $24 \mathrm{~h}$. The cells were cultured in medium containing 10\% FBS for $24 \mathrm{~h}$ and collected for cell cycle analysis by flow cytometry. The data shown in the right-hand panel are representative of three independent experiments. Representative profiles are shown in the left-hand panel. $\mathbf{b}$ The effect of miR-494 knockdown on cell cycle progression. After HCT-116 cells were transfected with the control miRNA inhibitor or the miR-494 inhibitor for $24 \mathrm{~h}$, cells were switched to conditioned medium without serum for $24 \mathrm{~h}$. The cells were then cultured in medium containing 10\% FBS for $24 \mathrm{~h}$ and collected for cell cycle analysis by flow cytometry. The data shown in the right-hand panel are representative of three independent experiments. Representative profiles are shown in the left-hand panel. c Colony formation assay. HCT-116 cells stably expressing the indicated miRNAs were maintained in culture media for 7 days and stained with crystal violet. The number of colonies in each condition was counted, and is expressed as a mean \pm S.D. from triplicate experiments. ${ }^{*}, P<0.05$ (Student's $t$-test). d The effect of miR-494 on cell proliferation. HCT-116 cells were transfected with the indicated constructs, and cell proliferation was measured by BrdU incorporation. Data are mean \pm S.D. from triplicate experiments. ${ }^{*}, P<0.05$ (Student's $t$-test). e The effect of miR-494 on cell proliferation. HCT-116 cells were transfected with a miR-494 mimic or with a miR-494 inhibitor. CCK8 assays were performed at 1, 2, 3, and 4 days post-transfection. Data are mean \pm S.D. from triplicate experiments. **, $P<0.01$; **, $P<0.001$, compared to Anti-Control. \#, $P<0.05$; \#\#, $P<0.01$; \#\#\#, $P<0.001$, compared to miR-Control, Student's t-test
\end{abstract}

\section{Western blot analysis}

Western blotting was performed as previously described (31). The commercial antibodies used were anti-APC (Abcam catalog no. 154906), anti- $\beta$-catenin (Santa Cruz catalog no. 7963), anti-cyclin D1 (Cell Signaling Technology catalog no. 2978S), and anti-fibrillarin (Abcam catalog no. ab5812).

\section{Colony formation assays}

HCT-116 cells were transfected with the indicated longlasting synthetic miRNAs. The commercial miRNAs used were a negative miR-control (Ribobio catalog no. miR04101-1-10), a miR-494 mimic (Ribobio catalog no. miR40002816-1-10), a negative anti-miR-control (Ribobio catalog no. miR03101-1-10), or an anti-miR494 (Ribobio catalog no. miR30002816-1-10). At $48 \mathrm{~h}$ post-transfection, cells were plated in triplicate at 500 cells per $60 \mathrm{~mm}$ dish. After 7 days, the colonies were stained with $0.1 \%$ crystal violet solution and counted using a light microscope.

\section{Flow cytometry}

Cells were harvested by trypsinization, washed with icecold PBS, and fixed in 70\% ice-cold ethanol in PBS. Before staining, cells were sedimented in a chilled centrifuge and resuspended in cold PBS. Bovine pancreatic RNase (Sigma-Aldrich) was added to a final concentration of $2 \mu \mathrm{g} / \mathrm{mL}$, and the cells were incubated at $37^{\circ} \mathrm{C}$ for $30 \mathrm{~min}$, followed by incubation with $20 \mu \mathrm{g} / \mathrm{mL}$ propidium iodide (Sigma-Aldrich) for $20 \mathrm{~min}$ at room temperature. The cell cycle profiles of $2 \times 10^{4}$ cells were analyzed using a FACSCalibur flow cytometer (BD Biosciences).

\section{Statistical analysis}

All experiments were repeated at least three times. Data shown are presented as mean \pm SD of three or more independent experiments. A Student's $t$-test was used for statistical analysis of data. Differences in clinicopathological characteristics between the two groups were examined by Fisher's and chi-square tests. All $P$-values were determined using two-sided tests and statistical significance was based on a $P$-value of 0.05 . Correlation analysis was performed using scatter plots and Pearson's correlation analysis. The correlation coefficients and the corresponding $P$-values were calculated by the cor.test function of R.

\section{Results}

miR-494 is overexpressed in colorectal cancer

The Dlk1-Dio3 region is located on human chromosome $14 \mathrm{q} 32$, and constitutes one of the largest miRNA clusters in the human genome [29]. Many of these miRNAs are differentially expressed in various cancers, as well as several other disease states [30]. The expression and roles of Dlk1-Dio3 region miRNAs in oncogenesis are very controversial and differ in different tissues [30]. We examined several miRNAs from the Dlk1-Dio3 region using a microarray-based expression analysis of 17 CRC tissues and matched non-tumor adjacent tissues. As shown in Fig. 1a, a comparative analysis indicated that miR-494 was differentially overexpressed in CRC tissue when compared to that in adjacent, non-tumor tissue from the same patient. We further conducted real-time PCR to analyze the expression of miR-494 in 30 nontumor adjacent tissues and 46 carcinoma tissues from CRC patients (Fig. 1b), as well as in the 17 pairs of carcinoma tissues and matched non-tumor adjacent tissues (Fig. 1c). The real-time PCR data was consistent with the microarray data. Taken together, these results indicate that miR-494 is upregulated in CRC.

\section{Upregulation of miR-494 is associated with advanced clinicopathological features of CRC}

To determine the clinical significance of miR-494 in CRC, we analyzed the association between miR-494 CRC tissue expression levels and various CRC clinicopathological parameters. The median miR-494 expression in all $46 \mathrm{CRC}$ patients was 12.116. Using the median expression level as a cutoff, the patients were 
divided into two groups, a high miR-494 expression group $(n=20)$, and a low miR-494 expression group $(n=26)$. As shown in Table 1 , miR-494 was significantly upregulated in CRC patients with a higher TNM stage $(P=0.004)$. We also found that there were increased miR494 levels in poorly differentiated CRC tissue compared to well-differentiated CRC tissue $(P=0.034)$. However, miR494 expression was not significantly correlated with age, gender, mutation in APC, or survival status.

\section{miR-494 promotes CRC cell proliferation}

To explore the role of miR-494 upregulation in the development and progression of $\mathrm{CRC}$, we examined its effects on cellular proliferation and tumorigenesis. The HCT-116 line was chosen as it expresses wild-type APC, and it is widely used in CRC research. Flow cytometry analysis revealed that overexpression of a miR-494 mimic caused an increase in the percentage of cells in $S$ phase, and a decrease in the percentage of cells in the G1/G0 phase. Conversely, suppression of miR-494 expression using a miR-494 inhibitor increased the percentage of cells in the G1/G0 phase (Fig. 2a and b). To investigate the role of miR-494 in colon tumorigenesis, a colony formation assay was performed, which revealed that miR-494 overexpression significantly increased the proliferation rate of CRC cells (Fig. 2c). We further

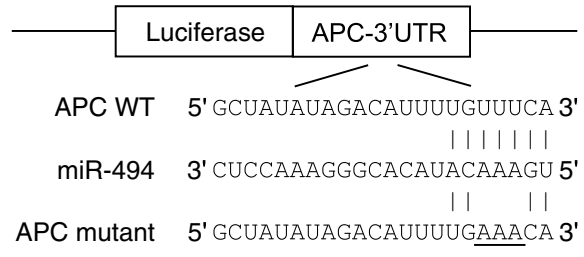

b
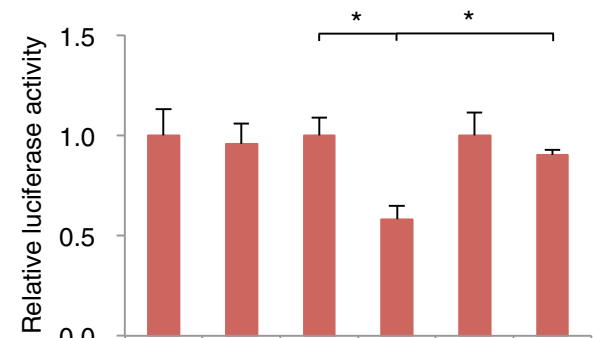

miR-Contro

miR-494

pGL3

APC-3'UTR WT

APC-3'UTR mutant

d

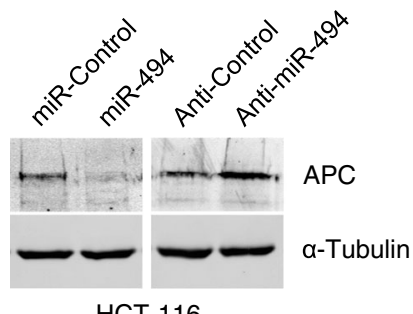

HCT-116
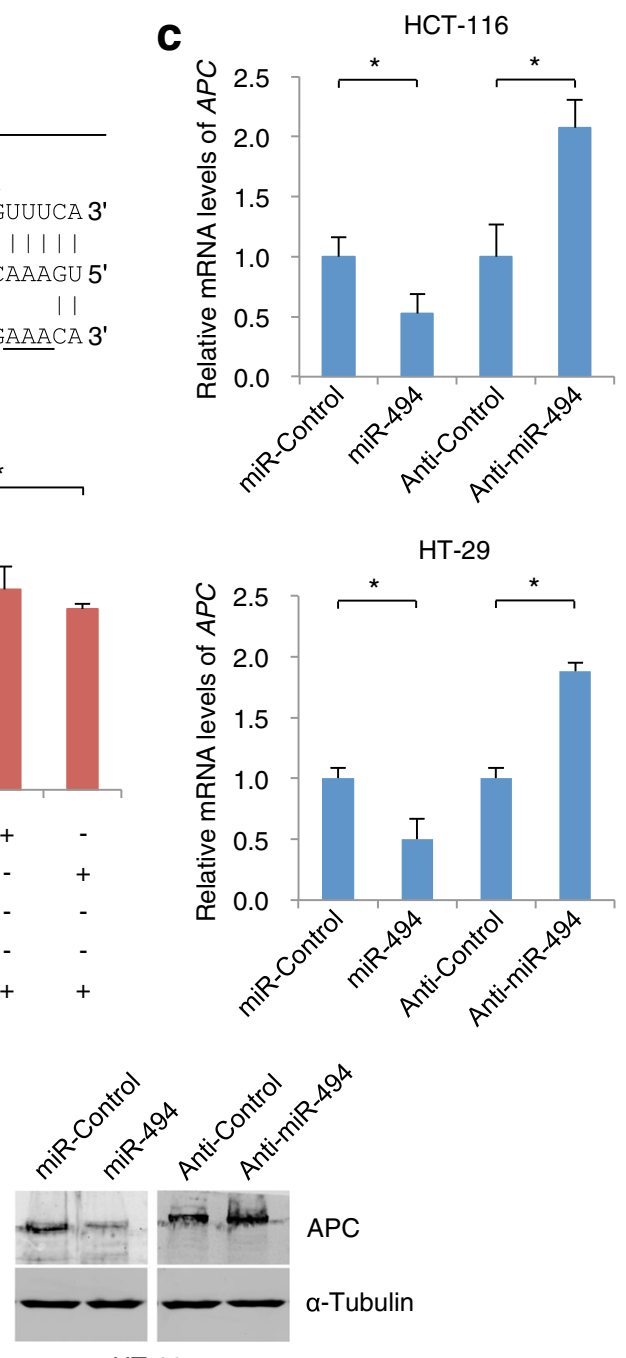

HT-29

Fig. 3 Luciferase reporter assays demonstrating the target relationship between miR-494 and APC mRNA. a Predicted miRNA binding sites within the 3'-UTR of APC mRNA. The pairing between miR-494 and the putative binding sites in the 3'-UTR of APC mRNA are shown. Mutations in the APC 3'-UTR are underlined. $\mathbf{b}$ Luciferase activity, normalized to renilla luciferase activity, was measured in homogenates of HEK293T cells transfected with the wild-type 3'-UTR and mutant 3'-UTR APC luciferase constructs and a miR-494 mimic or a scrambled miRNA control. c APC mRNA expression is reduced by the miR-494 mimic and increased by the miR-494 inhibitor. $\mathbf{d}$ Expression of APC protein is reduced by the miR-494 mimic and increased by the miR-494 inhibitor. (*, $P<0.05$, Student's $t$-test, $n=3$ independent experiments) 
examined the effects of suppressing miR-494 expression on CRC cell proliferation. Consistent with the abovementioned results, a colony formation assay showed that suppression of miR-494 expression dramatically inhibited the growth rate of HCT-116 CRC cells, as compared to control cells transfected with a control miRNA (Fig. 2c). To further demonstrate the importance of miR-494 in cell proliferation, we performed a BrdU incorporation assay, which is a more sensitive assay to measure cell proliferation. As a result, the number of BrdU-positive cells increased when miR-494 was overexpressed, whereas the number decreased when miR-494 was downregulated (Fig. 2d). A second cell proliferation study, conducted using a CCK8 assay, also indicated a role for miR-494 in positively regulating cell proliferation (Fig. 2e). Collectively, our data suggest that miR-494 may mediate CRC cell proliferation by regulating the G1/S transition.

\section{miR-494 directly targets APC in CRC cells}

Using a bioinformatics analysis, we identified putative binding sites for miR-494 within the 3'-UTR of the human APC mRNA (Fig. 3a). To validate APC as a miR494 target, we constructed a luciferase expression vector containing the 3 '-UTR segment of APC along with the putative miR-494 binding sites. Co-transfection of a miR-494 mimic and the APC 3'-UTR expression vector into HEK293T cells resulted in a significant suppression of APC luciferase activity. In addition, mutating the putative miR-494 binding sites completely eliminated this inhibitory effect (Fig. 3b). These data strongly suggest that APC is indeed the direct target of miR-494.

To examine whether miR-494 can directly target the APC mRNA in HCT-116 and HT-29 CRC cell lines, we transiently transfected the miR-494 mimic into HCT-116 and HT-29 cells. Endogenous APC mRNA and APC protein levels were then measured $48 \mathrm{~h}$ after transfection. As a result, the expression of both APC mRNA and APC protein decreased in the presence of the miR-494 mimic (Fig. 3c and d). In contrast, when HCT-116 and HT-29 cells were transfected with the miR-494 inhibitor, the APC mRNA and APC protein levels increased (Fig. 3c and d).

\section{Downregulation of APC is inversely correlated with miR-494 expression in CRC}

To further evaluate the relationship between miR-494 and $\mathrm{APC}$ in human CRC, we analyzed the expression of $\mathrm{APC}$ and miR-494 in paired CRC and non-tumor adjacent tissue using immunohistochemistry and real-time

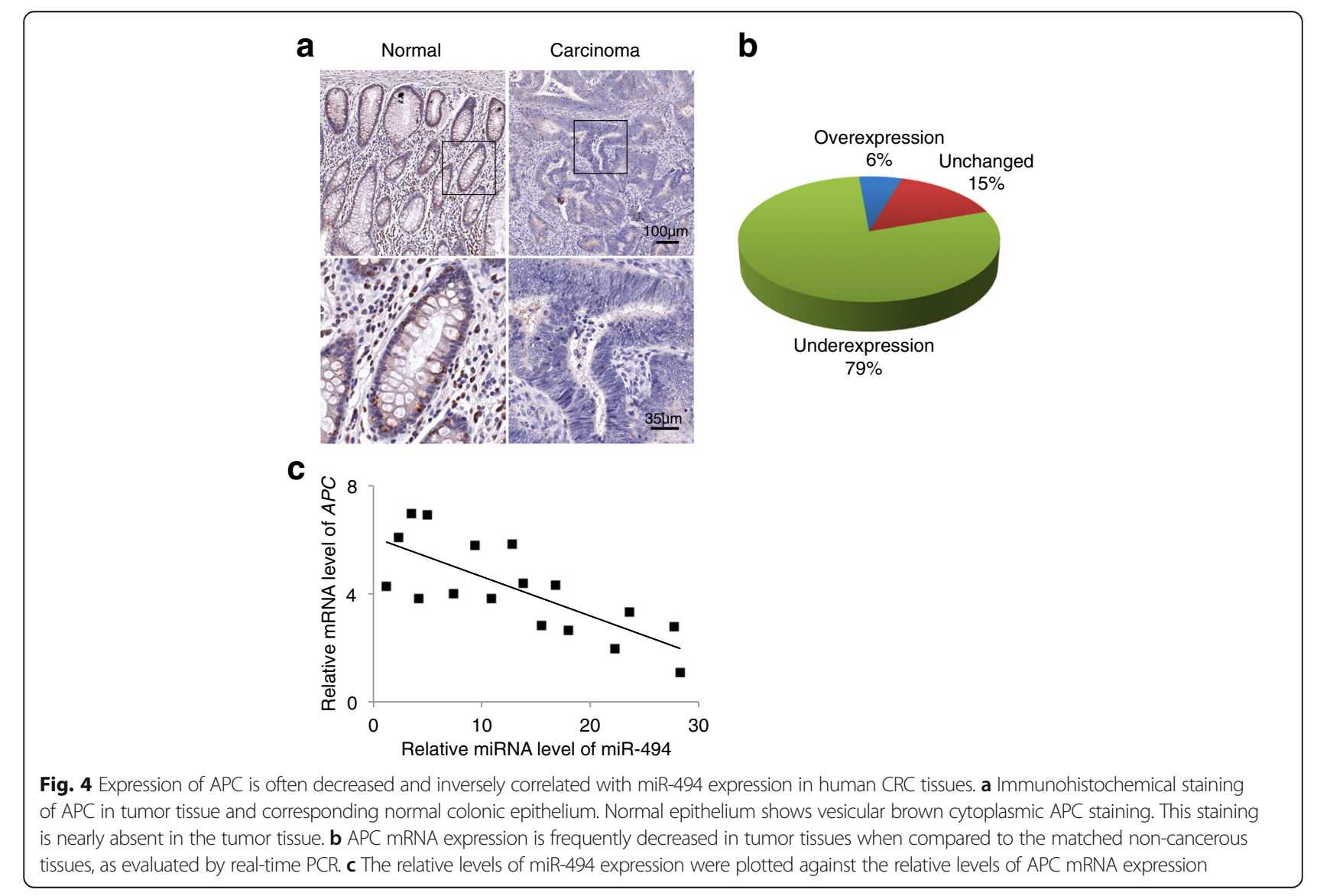


PCR. Using both immunohistochemistry (Fig. 4a) and real-time PCR (Fig. 4b), tumors showed decreased APC expression when compared with expression in tumoradjacent tissues. Furthermore, using real-time PCR, APC mRNA expression levels in tumor tissues were found to be inversely correlated with miR-494 levels (Fig 4c). This relationship had a Pearson's correlation coefficient of $-0.5679(P<0.0001)$, indicating a strong negative correlation between miR-494 and APC expression levels in colon carcinomas. Taken together, these data suggest that decreased APC expression may result from overexpression of miR-494 in human CRC.

\section{miR-494 activates the Wnt/B-catenin pathway}

Next, we investigated the functional relevance of the interaction between miR-494 and APC by determining the effects of changes in their expression levels on the activity of the Wnt pathway. First, we examined the effects of changes in miR-494 expression levels on the transcriptional activity of the TCF transcription factor. HCT-116 cells were transfected with a luciferase reporter construct harboring either three optimal TCF-binding sites (Topflash) or three mutated
TCF-binding sites (Fopflash). Transfection with the miR-494 mimic significantly increased Top/Fop transcriptional activity, whereas transfection with the miR-494 inhibitor significantly decreased Top/Fop transcriptional activity (Fig. 5a). Next, we examined the induction of c-Myc and cyclin D1 activity, important downstream target genes in the $\mathrm{Wnt} / \beta$-catenin pathway (35). We used luciferase reporter constructs under the control of promoters containing either of four Myc or cyclin D1 responsive elements. We observed an increase in both c-Myc and cyclin D1 reporter activities in cells co-transfected with the miR-494 mimic, and a corresponding decrease in $\mathrm{c}-\mathrm{Myc}$ and cyclin D1 reporter activity in cells co-transfected with the miR-494 inhibitor (Fig. 5b and c). Furthermore, cellular fractionation showed that miR-494 mimic overexpression promoted the nuclear accumulation of $\beta$-catenin (Fig. $5 \mathrm{~d}$ ), indicating that miR-494 activates the $\mathrm{Wnt} / \beta$-catenin signaling pathway by promoting nuclear $\beta$-catenin accumulation. Moreover, we observed an increase in the cyclin D1 protein, a Wnt/ $\beta$-catenin signaling pathway target gene, in cells overexpressing the miR-494 mimic (Fig. 5e). Thus, overexpression of miR-494 activates the Wnt/ $\beta$-catenin pathway.

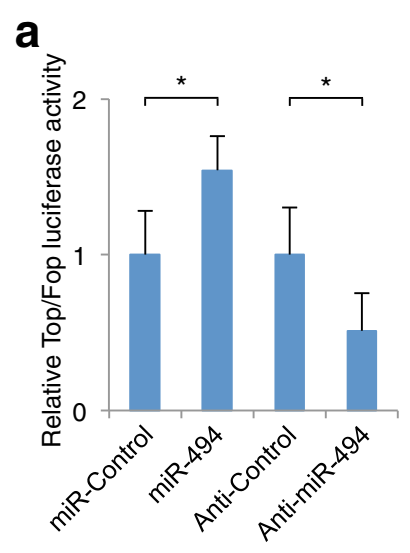

d

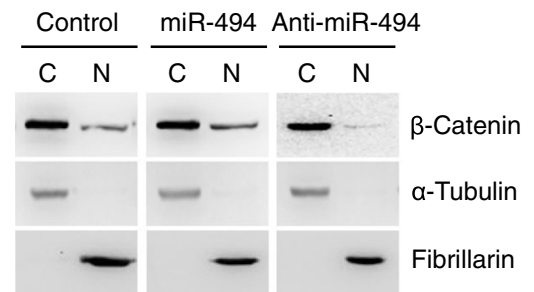

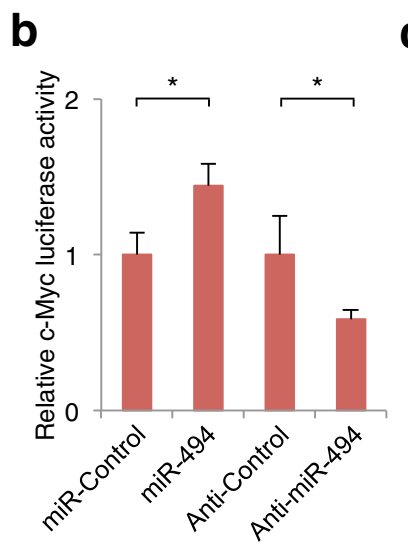

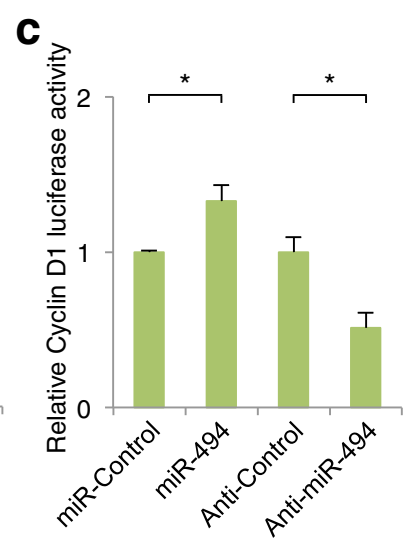

e

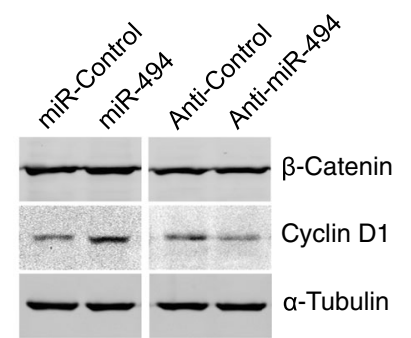

Fig. 5 miR-494 induces $\beta$-catenin signaling (Top/Fop, c-Myc, cyclin D1). a Dual luciferase assay demonstrating the effect on Top/Fop reporter activity in HCT-116 cells. Values were normalized to a renilla transfection control. The figure shown is a representative of at least three independent experiments. $\mathbf{b}$ Dual luciferase assay showing the effect of expression of a miR-494 mimic on a c-Myc reporter construct in HCT-116 cells. c Dual luciferase assay showing the effect of expression of a miR-494 mimic on a cyclin D1 reporter construct in HCT-116 cells. $\mathbf{d}$ Western blot analysis of $\beta$-catenin expression in the cytoplasm $(\mathrm{C})$ and nucleus $(\mathrm{N})$ of the indicated cells. a-tubulin and fibrillarin were measured by western blot to monitor the efficiency in the preparation of cytosolic and nuclear protein extracts, respectively. e Western blot analysis of $\beta$-catenin and cyclin D1 in the indicated cells. $\left(^{*}, P<0.05\right.$, Student's $t$-test, $n=3$ independent experiments) 


\section{Suppression of APC is functionally important for the biological effects of miR-494}

To explore the functional significance of APC depletion in upregulating the $\mathrm{Wnt} / \beta$-catenin pathway in colon cancer cell lines, as well as in the activation of $\beta$-catenin induced by miR-494, we studied the effects of APC depletion using specific siRNAs. As shown in Fig. 6a, b, and $\mathrm{c}$, siRNA silencing of APC expression enhanced the Top/Fop, c-Myc, and cyclin D1 transcriptional activities. In addition, silencing APC also increased Top/Fop, c-Myc and cyclin D1 transcriptional activities in HCT-116 cells whose miR-494 expression levels were suppressed (Fig. 6d, e, and f). These results demonstrate that APC lies downstream of miR-494 and is functionally important for miR-494-induced Wnt/B-catenin signaling in colon cancer cell lines.

\section{Discussion}

The key finding in this study is that miR-494 expression is markedly upregulated in CRC tissues compared to normal colorectal tissues. Furthermore, ectopic expression of miR-494 enhances the proliferation of CRC cells, whereas inhibition of miR-494 expression has the opposite effect. Moreover, we demonstrate that miR-494 upregulation in CRC cells activates the $\mathrm{Wnt} / \beta$-catenin pathway by directly targeting APC. These findings suggest that this dysregulation of miR-494 levels may play

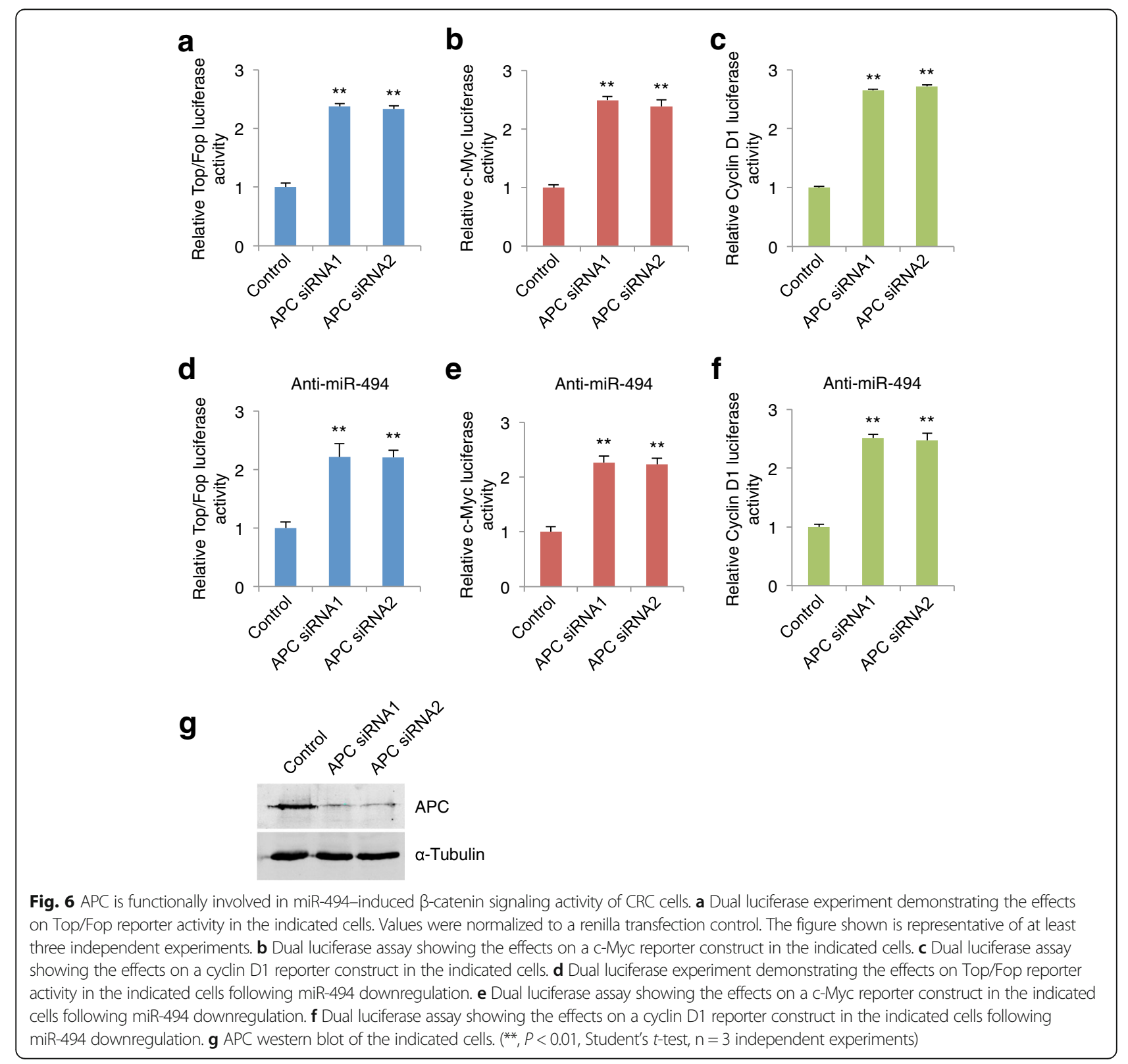


an important role in promoting proliferation and tumorigenesis in CRC.

Aberrant $\mathrm{Wnt} / \beta$-catenin signaling has been linked to the pathogenesis of various diseases, including cancer, and is thought to promote tumor progression [23-28]. Multiple key negative regulators, such as APC, GSK-3 $\beta$, and Axin, are suppressed in cancer, contributing to the promotion of tumor progression through regulation of the Wnt/ $\beta$-catenin pathway. For instance, inactivation of GSK-3 $\beta$ via kinases promotes mammary tumorigenesis by activation of the canonical Wnt pathway [31]. In mouse models, loss of APC function has been shown to lead to colorectal tumorigenesis through hyperactivation of Wnt/B-catenin signaling [32]. Herein, we demonstrate that miR-494 suppresses APC expression by directly targeting the 3'-UTR of the APC mRNA. Consistent with the tumor-suppressive effects of APC, miR-494 was upregulated in $\mathrm{CRC}$, and its overexpression dramatically promoted CRC cell proliferation.

The Wnt/ $\beta$-catenin signaling pathway is controlled at multiple levels. $\beta$-catenin is the major cellular effector of Wnt signaling and is normally retained by a degradation complex containing Axin, APC, GSK-3 $\beta$, and casein kinase $1 \mathrm{a}$. In the absence of Wnt, the complexed $\beta$-catenin is targeted for proteasome-mediated degradation following its phosphorylation and ubiquitination [33-35]. APC is crucial for the capture of $\beta$-catenin by the degradation complex, and binds $\beta$-catenin directly via its central armadillo repeats [36]. Upon Wnt activation, Axin is removed from the destruction complex allowing the release of $\beta$-catenin. The accumulated $\beta$-catenin enters the nucleus and binds to the TCF/LEF family of transcription factors to induce target gene expression [37, 38]. A key event therefore in both Wnt signal transduction and cancer cell proliferation is the regulation of $\beta$-catenin stability and activity. In this study, we have uncovered a mechanism for controlling APC expression, and thereby the activity of the Wnt pathway, through the action of miR-494, and suggest that miR-494 contributes to the pathogenesis of CRC.

miR-494 is a product of the Dlk1-Dio3 region, which is located on human chromosome 14q32, and constitutes one of the largest miRNA clusters in the human genome. The expression patterns of miR-494 are not consistent across different types of tumors, suggesting that there is tissue-dependent regulation of expression of this miRNA, among other potential mechanisms [39-44]. In this study, we demonstrated that miR-494 is upregulated in CRC tissues compared to adjacent, non-cancerous tissues from the same patient. Furthermore, we demonstrated that ectopic miR-494 expression increases the growth rate of HCT-116 cells compared to a control miRNA, whereas suppression of miR-494 expression inhibited cell proliferation and colony formation. The data strongly suggest that upregulation of miR-494 correlates with clinical CRC progression and that miR-494 may function as an onco-miRNA.

\section{Conclusions}

Our study has shown that elevated expression of miR494 promotes cell proliferation and tumorigenesis in CRC by suppressing the expression of APC, an inhibitor of $\beta$-catenin signaling. These findings uncover a novel molecular mechanism for the hyperactivation of the Wnt/ $\beta$-catenin signaling pathway in CRC, suggesting that miR-494 may serve as a potential therapeutic target for the treatment of CRC.

\section{Abbreviations \\ APC: Adenomatous polyposis coli; CRC: Colorectal cancer; DAB: Diaminobenzidine; DMEM: Dulbecco's modified Eagle's medium; FBS: Fetal bovine serum; GSK-3ß: Glycogen synthase kinase 3 beta; IHC: Immunohistochemistry; miRNAs: MicroRNAs; PTEN: Phosphatase and tensin homolog; TCF/LEF: T-cell factor/lymphoid enhancer binding factor; TNM: Tumor-Node-Metastasis}

\section{Acknowledgements}

The authors wish to thank; the patients involved in the study and their guardians; Xin Tong for providing CRC tissue; Meng Wang for providing the APC 3'-UTR vector construct; and Haixi Sun for bioinformatic analysis. We also thank all members of our group for discussions and assistance with this study.

\section{Funding}

This work was supported by the National Natural Science Foundation of China (31471395 to Q.Z. and 31621004) and the Key Research Projects of the Frontier Science of the Chinese Academy of Sciences (QYZDY-SSW-SMC002 to Q.Z.).

\section{Availability of data and materials}

The dataset (s) supporting the findings of this study are included in the article.

\section{Authors' contributions}

$\mathrm{QZ}, \mathrm{WL}$, and $\mathrm{YZ}$ conceived the project idea and designed the experiments; $Y Z, L G$, $Y L, F$, performed the experiments; GF and $Y Z$ analyzed the data; $Q Z, W L$, and $Y Z$ wrote the manuscript. All authors read and approved the final manuscript.

Ethics approval and consent to participate

The procedures of this study were approved by the Ethics Committee of Institute of Zoology.

Consent for publication

Not applicable.

\section{Competing interests}

The authors declare that they have no competing interests.

\section{Publisher's Note}

Springer Nature remains neutral with regard to jurisdictional claims in published maps and institutional affiliations.

Received: 26 June 2017 Accepted: 26 December 2017

Published online: 05 January 2018

\section{References}

1. Harrison S, Benziger $\mathrm{H}$. The molecular biology of colorectal carcinoma and its implications: a review. Surgeon. 2011;9(4):200-10.

2. Pandurangan AK. Potential targets for prevention of colorectal cancer: a focus on PI3K/Akt/mTOR and Wnt pathways. Asian Pac J Cancer Prev. 2013; 14(4):2201-5.

3. Miyaki $\mathrm{M}$, et al. Characteristics of somatic mutation of the adenomatous polyposis coli gene in colorectal tumors. Cancer Res. 1994;54(11):3011-20. 
4. Powell SM, et al. APC mutations occur early during colorectal tumorigenesis. Nature. 1992;359(6392):235-7.

5. Coppede F, et al. Genetic and epigenetic biomarkers for diagnosis, prognosis and treatment of colorectal cancer. World J Gastroenterol. 2014 20(4):943-56.

6. Morin PJ, et al. Activation of beta-catenin-Tcf signaling in colon cancer by mutations in beta-catenin or APC. Science. 1997;275(5307):1787-90.

7. Munemitsu $S$, et al. Deletion of an amino-terminal sequence beta-catenin in vivo and promotes hyperphosporylation of the adenomatous polyposis coli tumor suppressor protein. Mol Cell Biol. 1996;16(8):4088-94.

8. MacDonald BT, Tamai K, He X. Wnt/beta-catenin signaling: components, mechanisms, and diseases. Dev Cell. 2009;17(1):9-26.

9. Ikeda S, et al. Axin, a negative regulator of the Wnt signaling pathway, forms a complex with GSK-3beta and beta-catenin and promotes GSK-3betadependent phosphorylation of beta-catenin. EMBO J. 1998;17(5):1371-84.

10. Sancho E, Batlle E, Clevers H. Live and let die in the intestinal epithelium. Curr Opin Cell Biol. 2003;15(6):763-70.

11. Liu F, et al. Wnt-beta-catenin signaling initiates taste papilla development. Nat Genet. 2007;39(1):106-12

12. Ambros V. The functions of animal microRNAs. Nature. 2004;431(7006):350-5.

13. Bartel DP. MicroRNAs: genomics, biogenesis, mechanism, and function. Cell. 2004;116(2):281-97.

14. He L, Hannon GJ. MicroRNAs: small RNAs with a big role in gene regulation. Nat Rev Genet. 2004;5(7):522-31.

15. Song SJ, et al. MicroRNA-antagonism regulates breast cancer Stemness and metastasis via TET-family-dependent chromatin remodeling. Cell. 2013;154(2):311-24.

16. Song SJ, et al. The Oncogenic MicroRNA miR-22 targets the TET2 tumor suppressor to promote hematopoietic stem cell self-renewal and transformation. Cell Stem Cell. 2013;13(1):87-101.

17. Valencia-Sanchez MA, et al. Control of translation and mRNA degradation by miRNAs and siRNAs. Genes Dev. 2006;20(5):515-24.

18. Miranda KC, et al. A pattern-based method for the identification of MicroRNA binding sites and their corresponding heteroduplexes. Cell. 2006; 126(6):1203-17.

19. Zhang B, et al. microRNAs as oncogenes and tumor suppressors. Dev Biol. 2007;302(1):1-12.

20. Voorhoeve PM, et al. A genetic screen implicates miRNA-372 and miRNA373 as oncogenes in testicular germ cell tumors. Cell. 2006;124(6):1169-81.

21. Kayani $M$, et al. Role of miRNAs in breast cancer. Asian Pac J Cancer Prev. 2011;12(12):3175-80.

22. Kong YW, et al. microRNAs in cancer management. Lancet Oncol. 2012; 13(6):e249-58.

23. Zhang $Y$, et al. Hepatitis C virus-induced up-regulation of microRNA-155 promotes hepatocarcinogenesis by activating Wnt signaling. Hepatology. 2012;56(5):1631-40.

24. Asangani IA, et al. MicroRNA-21 (miR-21) post-transcriptionally downregulates tumor suppressor Pdcd4 and stimulates invasion, intravasation and metastasis in colorectal cancer. Oncogene. 2008;27(15): 2128-36.

25. Huang Z, et al. MicroRNA-95 promotes cell proliferation and targets sorting Nexin 1 in human colorectal carcinoma. Cancer Res. 2011;71(7):2582-9.

26. Subramanian M, et al. MiR-29b downregulates canonical Wnt signaling by suppressing coactivators of beta-catenin in human colorectal cancer cells. J Cell Biochem. 2014;115(11):1974-84.

27. Sun HB, et al. miR494 is an independent prognostic factor and promotes cell migration and invasion in colorectal cancer by directly targeting PTEN. Int J Oncol. 2014;45(6):2486-94

28. Wang $H$, Ach RA, Curry B. Direct and sensitive miRNA profiling from lowinput total RNA. RNA. 2007;13(1):151-9.

29. Edwards CA, et al. The evolution of the DLK1-DIO3 imprinted domain in mammals. PLoS Biol. 2008:6(6):e135.

30. Benetatos $\mathrm{L}$, et al. The microRNAs within the DLK1-DIO3 genomic region: involvement in disease pathogenesis. Cell Mol Life Sci. 2013;70(5):795-814.

31. Farago $\mathrm{M}$, et al. Kinase-inactive glycogen synthase kinase 3 beta promotes Wnt signaling and mammary tumorigenesis. Cancer Res. 2005;65(13):5792-801.

32. Korinek V , et al. Constitutive transcriptional activation by a beta-catenin-Tcf complex in APC-/- colon carcinoma. Science. 1997;275(5307):1784-7.

33. Willert K, Nusse R. Beta-catenin: a key mediator of Wnt signaling. Curr Opin Genet Dev. 1998;8(1):95-102.

34. Akiyama T. Wnt/beta-catenin signaling. Cytokine Growth Factor Rev. 2000;11(4):273-82
35. Wu G, et al. Inhibition of GSK3 phosphorylation of beta-catenin via phosphorylated PPPSPXS motifs of Wnt coreceptor LRP6. PLoS One. 2009:4(3):e4926.

36. Xing $Y$, et al. Crystal structure of a beta-catenin/APC complex reveals a critical role for APC phosphorylation in APC function. Mol Cell. 2004;15(4):523-33.

37. Mikels AJ, Nusse R. Wnts as ligands: processing, secretion and reception. Oncogene. 2006:25(57):7461-8.

38. Angers S, Moon RT. Proximal events in Wht signal transduction. Nat Rev Mol Cell Biol. 2009;10(7):468-77.

39. Liu L, et al. Overexpressed miR-494 down-regulates PTEN gene expression in cells transformed by anti-benzo(a)pyrene-trans-7,8-dihydrodiol-9,10epoxide. Life Sci. 2010;86(5-6):192-8.

40. Liu $Y$, et al. MicroRNA-494 is required for the accumulation and functions of tumor-expanded myeloid-derived suppressor cells via targeting of PTEN. J Immunol. 2012;188(11):5500-10.

41. Romano $\mathrm{G}$, et al. MiR-494 is regulated by ERK1/2 and modulates TRAILinduced apoptosis in non-small-cell lung cancer through BIM downregulation. Proc Natl Acad Sci U S A. 2012;109(41):16570-5.

42. Lim L, et al. MiR-494 within an oncogenic MicroRNA megacluster regulates G1/S transition in liver tumorigenesis through suppression of MCC. Hepatology. 2013;59(1):202-15.

43. Ohdaira $\mathrm{H}$, et al. MicroRNA-494 suppresses cell proliferation and induces senescence in A549 lung cancer cells. Cell Prolif. 2012:45(1):32-8.

44. Olaru AV, et al. MicroRNA down-regulated in human cholangiocarcinoma control cell cycle through multiple targets involved in the G1/S checkpoint. Hepatology. 2011;54(6):2089-98.

\section{Submit your next manuscript to BioMed Central and we will help you at every step:}

- We accept pre-submission inquiries

- Our selector tool helps you to find the most relevant journal

- We provide round the clock customer support

- Convenient online submission

- Thorough peer review

- Inclusion in PubMed and all major indexing services

- Maximum visibility for your research

Submit your manuscript at www.biomedcentral.com/submit

) Biomed Central 